\title{
The Role of Avoidance Coping and Escape Motives in Problematic Online Gaming: A Systematic Literature Review
}

\author{
Fiordalisa Melodia $^{1} \cdot$ Natale Canale $^{1} \cdot$ Mark D. Griffiths $^{2}$
}

Accepted: 23 October 2020 / Published online: 30 November 2020

(C) The Author(s) 2020

\begin{abstract}
Over the past two decades, research into Internet Gaming Disorder (IGD) has markedly increased due to worldwide spread of online videogames. The reasons and motivations for playing greatly contribute to its popularity. Escapism and avoidance coping strategies have been studied extensively and conceptualized as motives to play. A growing research base has demonstrated a strong association between these motives to play and negative gaming outcomes. Consequently, the aim of the present systematic review was to provide a comprehensive overview of the role of avoidance coping and escape motives in problematic online gaming. A systematic literature search was carried out using academic databases and a total of 26 empirical studies met the inclusion criteria. The results show that escapism and avoidance coping represent both a predictor of IGD and play a mediating role between many psychological factors (e.g., self-esteem, loneliness, selfconcept, anxiety) and problematic online gaming. However, the review also highlights the paucity of longitudinal studies that hinder the determination of the causal direction of these associations. Despite this limitation, the evidence has important implication for developing more effective prevention programs and clinical interventions.
\end{abstract}

Keywords Problematic online gaming · Internet gaming disorder · Avoidance · Escapism • Motives to play

Behavioral addictions (i.e., addictions that do not involve the ingestion of a psychoactive substance) are becoming increasing commonplace in modern society, particularly online addictions which are inextricably linked to the way humans now live, continued technological advancement, increased opportunity and availability, and the instant gratifications that such

Mark D. Griffiths

mark.griffiths@ntu.ac.uk

1 Department of Developmental Psychology and Socialisation, University of Padova, Padova, Italy

2 International Gaming Research Unit, Psychology Department, Nottingham Trent University, 50

Shakespeare Street, Nottingham NG1 4FQ, UK 
technologies provide. One such area is that of gaming addiction (Alonso-Fernández 1999). Griffiths (1995, 1996, 2005, 2009) argued that all addictions share more commonalities than differences and identified six particular characteristics: mood modification, whereby activities and psychoactive substances give a subjective sensation of pleasure such as calming or exciting effects; tolerance whereby an individual needs an increasing quantity or amount of time to obtain the same initial mood-modifying effects; withdrawal symptoms whereby when the behavior is interrupted or reduced, the individual experiences unpleasant feeling states and/ or physical effects, e.g., irritability, shakes, moodiness; conflict whereby there are conflicts between individuals and those around them (interpersonal conflicts), negative impacts on their occupation and/or education (inter-activity conflicts), and within individuals themselves (intrapsychic conflicts), caused by the chronic use of the substance or by dysfunctional behavior; relapse whereby there is a tendency to restart the activity or the use the substance again after a period of interruption; and salience whereby the substance or behavior constantly dominates the thoughts, feelings, and behavior of individuals.

A number of researchers have argued that it is important not to overpathologize common behaviors that occur in the online digital environment (e.g., gaming, shopping) and to determine exclusion criteria for excessive behaviors that should not be considered pathological (Kardefelt-Winther et al. 2017). On the other hand, other researchers support the idea that pathological internet-related behavior should be regarded most appropriately as a behavioral addiction (Brand et al. 2016; Weinstein et al. 2017). Currently, problematic gaming is considered a potential disorder, introduced into the Section III, "Emerging Measures and Models," of the latest (fifth) edition of the Diagnostic and Statistical Manual of Mental Disorders (DSM-5; American Psychiatric Association 2013) in the form of internet gaming disorder (IGD). To diagnose this disorder, it is necessary that this condition persists for more than 12 months and five criteria or more (out of nine) need to be endorsed. The nine IGD criteria comprise the following: (i) preoccupation with internet games; (ii) withdrawal symptoms when internet gaming is not possible (irritability, anxiety, or sadness); (iii) tolerance; (iv) unsuccessful attempts to limit participation in internet games; (v) loss of interest in previous hobbies and entertainment as a result of, and with the exception of, internet games; (vi) continued excessive use of internet games despite awareness of psychosocial problems; (vii) deception of family members, therapists, or others about the amount of internet gaming; (viii) use of internet games to escape or mitigate negative moods (e.g., despair, guilt, anxiety); and (ix) jeopardizing or losing a relationship, a job, or an educational or a significant career opportunity due to participation in internet games. These diagnostic criteria mainly originated from a combination of pre-existing clinical criteria and unofficial conditions such as gambling disorder, substance use disorder, and generalized internet addiction (Kuss et al. 2017).

In the literature, the online gaming genre that has been most researched is Massively Multiplayer Online Role-Playing Games (MMORPGs). In MMORPGs, a very large number of players assume the role of the character in a persistent detailed open virtual world, usually a fantasy world. A game's storyline evolves in real time, and individuals must collaborate with other players in the game to succeed in more complex goals. Research has identified strong associations between problematic behavior in MMORPGs and the escapism motive (i.e., avoidance of real-life problems), role-playing (i.e., assuming the role of an in-game character), and personalization of character (Kuss et al. 2012). Two other popular online game genres that have increasingly been researched are Multiplayer Online Battle Arena (MOBA) games and First-Person Shooter (FPS) games. MOBA games involve relatively short team matches (30- 
$60 \mathrm{~min}$ ) in which a single character, as part of a team, battles against other teams, and FPS games involve players in combat with enemies from a first-person perspective.

A lot of research has concentrated on the more negative aspects of gaming such as psychosocial problems (Kuss and Griffiths 2012), aggressive/oppositional behavior and hostility (Griffiths 1999), psychiatric distress (Pontes 2017), dysfunctional coping, poor school performance (Gentile et al. 2004), lower self-esteem (Griffiths 1996), loneliness (Lemmens et al. 2011), perceived stress (Canale et al. 2019), and maladaptive cognitions (Kaczmarek and Drążkowski 2014). Moreover, medical and psychosomatic problems have been found to be consequences of IGD including sleep abnormalities, elevated risk for premature mortality, chronic diseases (such as obesity, cardiovascular disease, high blood pressure, triglycerides, high-density lipoprotein cholesterol) (Katzmarzyk 2010), unfavorable changes in hemodynamic parameters (Borusiak et al. 2008), and physical injuries related to repetitive strain (Zapata et al. 2006).

With the proliferation of online games, there has been increasing concern over the excessive use of gaming and its impact on psychological well-being. In modern society, videogames represent a widespread and popular leisure activity and are played in millions of homes worldwide. The videogame industry is continuously growing and developing, and 2018 was a record-breaking year for videogame industry, with total videogame sales exceeding $\$ 43.4$ billion, and growing at several times the rate of the overall economy (ESA, 2019). The gaming industry is expected to further grow and virtual reality gaming has likely become the backbone of the future gaming industry (Mordor Intelligence 2019).

\section{Compensatory Internet Use Model}

In the field of internet addictions, some authors (e.g., Kardefelt-Winther 2014, 2017; Snodgrass et al. 2014) have noted the tendency to examine internet use disorders (including problematic online gaming) only from the perspective of addiction. They have argued that an addiction perspective, grounded in the knowledge of substance addictions, has hindered the study of internet use disorders, and claiming such a perspective does not contribute much to improving the comprehension of the antecedents and etiology that facilitate their onset and development.

Scholars are in disagreement concerning a unifying a theory of addiction although some empirical findings indicate coping and compensation as major underlying contributors for internet use disorders. For instance, Armstrong et al. (2000), investigating the psychological risk factors for internet addictions, found out that problematic internet users generally used the internet for an avoidance reason, and viewed the behavior as a coping strategy rather than an addiction. Similarly, a study conducted by Lemmens et al. (2011) suggested that pathological online gaming may be a way to avoid real-life problems (e.g., loneliness, low self-esteem), through virtual social relationships or achievements. Here, environmental stressors might cause different psychosomatic strains that players can avoid through the cognitive distraction of gaming and, in the long-term, could lead to pathological online gaming (Snodgrass et al. 2014).

The basic principle of the compensatory internet use model is that the source of the issue is a response given by the individual to their negative life situation, facilitated by an internet application, such as social media use, online gambling, or online gaming (Kardefelt-Winther 2014). For instance, if the individual's life is characterized by a lack of adequate social 
stimulation, they tend to be more motivated to go online to interact and that is made easier by the employment of applications where socializing is provided, such as online videogames or social networking sites. Moreover, Scerri et al. (2019) pointed out that need-fulfillment deficits were associated with IGD. Therefore, in the compensatory model, the motivations for the use of online applications are based on psychosocial issues or unsatisfied real-life needs.

\section{Motives to Play}

The captivation of videogames appears to lie in their potential to fulfill various psychological needs that can be conceptualized as motives to play. Demetrovics et al. (2011) identified seven motivational dimensions for online gaming: social motivation, escape, competition, skill development, coping, fantasy, and recreation. Escape and coping, especially avoidance coping strategies, have been studied extensively (Deleuze et al. 2019; Brand et al. 2014; Brand et al. 2014; Laconi et al. 2017). Although separate constructs, escape and avoidant coping are highly correlated with each other. While escapism emphasizes leaving reality, avoidance strategies emphasize the game's capability to help cope with real problems (stress, aggression, anxiety), by helping individuals manage unpleasant moods and unwanted impulses. In the context of addictions, many studies report a higher use of avoidance strategies to cope with life problems and the seeking of a temporary escape from reality, in the same way that individuals use of substances like alcohol (Bacharach et al. 2008), or behaviors like gambling (Bergevin et al. 2006; Blaszczynski and Nower 2002) and online gaming (Hussain and Griffiths 2009; Demetrovics et al. 2011; Przybylski et al. 2010; Hemenover and Bowman 2018).

Coping is a multifaceted and complex construct. When individuals face a stressful event, they can implement a series of emotional, cognitive, and/or behavioral responses. These responses depend on the subjective evaluation of the stressful event and on the perception of control on it. Lazarus and Folkman (1984) defined coping as "persistently changing cognitive and behavioral efforts in order to manage specific external and/or internal demands that are seen as taxing or exceeding the resources of the person" (p.141). The outcomes of this process can be adaptive or maladaptive depending on whether the individual has been able to cope with the stressors adequately. The transactional model proposed by Lazarus and Folkman (1984) emphasizes two types of coping: problemfocused coping includes the active search of information, solutions to the problem, and behaviors aimed at modifying the circumstances at the origin of the stressful event, so it is used in situations perceived as more easily controlled; emotion focused coping is aimed at regulating emotions through their expression and modulation and can be considered less adaptive. Emotion focused coping includes ventilation of feelings or avoiding problems, such as self-blame, anger, self-distraction, withdrawal, and/or use of drugs. It is known that dysfunctional coping strategies, especially emotion focused and avoidant coping strategies predict risky behaviors among adolescents (Cooper et al. 2003) and play a role in the relationship between stressful life events and the etiology of psychiatric disorders (Lazarus and Folkman 1984; Rohde et al. 1990) such as anxiety and depression (Ebata and Moos 1991; Donovon and Spence 2000), whereas problem-focused coping promotes healthier behaviors (Stein and Nyamathi 1998). Coping strategies change during adolescent development and the development of characteristic ways of coping in childhood and adolescence may be precursors to patterns of coping in adulthood (Compas et al. 2001). 
The escape motive refers to the intentional involvement in playing videogames to detach from the real world, to immerse into a fantasy world, and/or avoid real-life problems (Caplan et al. 2009). Escapism offers momentary fulfillment and gratification through the use of fanciful scenarios, whether through active participation (e.g., playing online games) or passive observation (e.g., watching movies or series) (Ebata and Moos 1991). Additionally, Evans (2001) suggest that escapism is a construct encompassing both psychological immersion and engagement of fantasy.

Yee (2006) developed a 10-factor model of motivation for MMORPG players that were grouped into three main headings: achievement, which encompasses advancement, mechanics, and competition; social which includes socializing, relationships, and teamwork; and immersion, which includes discovery, role-playing, customization, and escapism. Online videogames, and in particular MMORPGs, offer highly immersive experiences, allowing the player to experience a strong sense of presence in the imaginative game world. Therefore, escapism expands beyond simple psychological immersion, encompassing a believable absorption into the persistent, three-dimensional world (Warmelink et al. 2009). In order to develop prevention programs aimed at promoting moderate and responsible gaming, practitioners and research need to have a good knowledge of the motives as to why people participate in gaming.

\section{The Present Study}

The aim of the present study was to review and synthesize empirical research examining the role that escapism and avoidant coping motives play in problematic online gaming. Although escapism and avoidant coping are separate constructs, they are highly correlated with each other and researchers tend to offer no uniform definition in literature when investigating escapism as a motivation for online gaming. Scholars have generally not provided a clear distinction between escapism and avoidance, and the terms escapism and avoidance are often used interchangeably. This conceptual inconsistency makes it difficult to interpret findings if the researcher is unclear in communicating the meaning of these constructs in the first place. Therefore, clarifying the nature of escapism as an avoidant coping strategy should be seen as the basis for further research on this topic. Given the importance of this motive, the present literature review synthesizes the available research that has examined the role of avoidance coping strategies or escape in developing of problematic online gaming, according to Preferred Reporting Items for Systematic Reviews and Meta-Analyses (PRISMA) guidelines.

\section{Method}

The review was conducted utilizing the PRISMA guidelines (Moher et al. 2009). In February 2020, a literature search was carried out via the following database: PubMed, ProQuest, Web of Science, Google Scholar and EBSCO that included Academic Search Complete, PsycARTICLES, and PsycINFO. The researches were conducted using the following search terms: gam* AND (addict* OR compuls* OR depend* OR problem* OR disorder) AND coping strategies OR avoidan* OR escape. Additionally, references reported in relevant studies identified were hand-searched to see if there were additional papers for inclusion in the review. Due to the inconsistent definition of "internet gaming addiction", papers which had "internet addiction" in their titles or in the abstract were considered, but only studies that assessed gaming addiction, gaming disorder, or problematic gaming use were included in the review. The inclusion criteria for the studies in the present review were: (i) being an empirical study comprising primary data (ii) published in a peer-reviewed paper from 2010 to 2020, (iii) 
citing avoidance coping strategies, or escape as a motive for gaming, and (iv) having a sample size with more than 500 participants. Additionally, studies were excluded if they (i) had less than 500 participants, (ii) were qualitative studies, reviews, theoretical papers, or psychometric validation studies, (iv) were not published in the English language, and (iv) assessed escape as a symptom according to problematic gaming criteria (e.g., the DSM-5 escape criterion).

\section{Study Selection}

The database search parameters (full text, being published from 2010 to 2020 and in English language) yielded a total of 1859 hits, and 26 papers, reported in references lists, were handsearched. The full study selection process is described in the PRISMA flow diagram (Fig. 1). The title and abstract of each study was examined. A total of 1764 publications were excluded because of unsuitability for the present review based on the inclusion and exclusion criteria. Consequently, 121 full texts of the papers were deemed suitable, for further examination to determine whether they could be included in the review. From 121 papers, 95 studies were excluded due to escape being assessed as a symptom according to DSM-5 $(n=2)$, no specific assessment of avoidance coping strategies or escape motives $(n=12)$, and no specifically referring to gaming $(n=20)$. Additionally, qualitative studies $(\mathrm{n}=2)$, psychometric validation studies $(n=11)$, reviews $(n=2)$, and theoretical studies $(n=2)$ were excluded. Finally, studies with less than 500 participants $(n=44)$ were excluded. Following this process, a total of 26 studies were identified for inclusion in the present review. Table 1 provides a summary regarding detailed characteristics of included studies.

\section{Results}

\section{Country of Origin}

Concerning the country where the data of the included studies were collected, eight were crosscultural studies. These eight studies collected data from (i) Australia, Europe, USA, Brazil, and smaller cohorts from a number of other countries (Loton et al. 2016), (ii) North and South America, Europe, Africa, and Australasia (Maroney et al. 2019), (iii, iv) Belgium, Switzerland, and France (Billieux et al. 2013, 2015), (v) Hungary, UK, Italy, Norway, Slovenia, France, Romania, and Korea (Kim et al. 2016), (vi) France, Italy and UK (Dauriat et al. 2011), (vii) Hungary, Romania, and Slovakia (Bányai et al. 2019) and the last study collected data from 45 countries (the majority of participants were from the UK) (Kirby et al. 2014). Data from the remaining studies were collected from Hungary $(n=2$; Király et al. 2015, 2017), Germany $(n=$ 3; Von Der Heiden et al. 2019; Rosenkranz et al. 2017; Dreier et al. 2017), China ( $n=2$; Li et al. 2016; Zhengchuan Xu et al. 2012), Sweden ( $n=2$; Hellström et al. 2012, 2015), UK $(n=2$; Kardefelt-Winther 2014a, b), Australia (Schneider et al. 2018), Croatia (Šporčić and GlavakTkalić 2018), Italy (Milani et al. 2018), Canada (Biegun et al. 2020), Poland (Kaczmarek and Drążkowski 2014), Korea (Kwon et al. 2011), and Perù (Ramos-Diaz et al. 2018).

\section{Participants' Characteristics}

The studies reviewed comprised a total of 48,573 participants. Concerning the age of the samples, ten studies comprised both adolescent and adult samples (Király et al. 2015; Bányai 


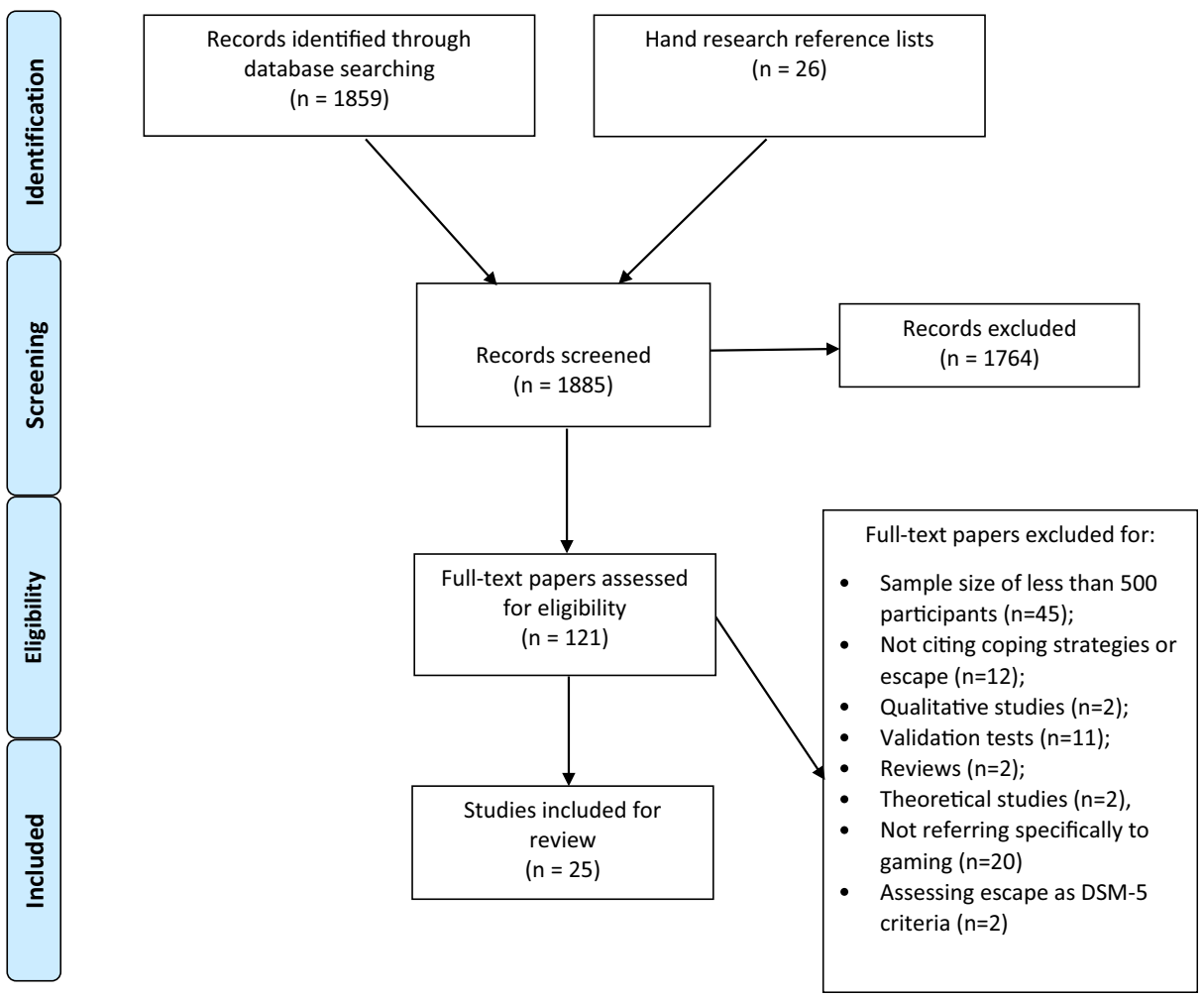

Fig. 1 PRISMA flow diagram of papers selected for systematic review

et al. 2019; Maroney et al. 2019; von der Heiden et al. 2019; Kardefelt-Winther 2014a, b; Kaczmarek and Drążkowski 2014; Dauriat et al. 2011; Ramos-Diaz et al. 2018; Király et al. 2017), six only adult samples (Loton et al. 2016; Šporčić and Glavak-Tkalić 2018; Billieux et al. 2013, 2015; Kim et al. 2016; Kirby et al. 2014), eight studies comprised school students from nine to 19 years old (Milani et al. 2018; Schneider et al. 2018; Rosenkranz et al. 2017; Kwon et al. 2011; Dreier et al. 2017; Hellström et al. 2012, 2015; Xu et al. 2012), and two studies comprised university students (Biegun et al. 2020; Li et al. 2016). Eleven studies comprised gamers without specifying the type of videogame played (Milani et al. 2018; Loton et al. 2016; Schneider et al. 2018; von der Heiden et al. 2019; Biegun et al. 2020; Rosenkranz et al. 2017; Kwon et al. 2011; Dreier et al. 2017; Kim et al. 2016; Király et al. 2017; Xu et al. 2012), five studies comprised World of Warcraft players (Kardefelt-Winther 2014a, b; Billieux et al. 2013, 2015; Kirby et al. 2014), two studies comprised MMORPG players (Kaczmarek and Drążkowski 2014; Dauriat et al. 2011), two studies comprised MMOPRG and FPS players (Király et al. 2015; Maroney et al. 2019), and two studies comprised general gamers and MMORPG players (Hellström et al. 2012, 2015). Samples of the four remaining studies comprised recreational and esport gamers (Bányai et al. 2019), FPS, role-playing, adventures, MOBA and MMORPG players (Šporčić and Glavak-Tkalić 2018), addicted and non-addicted general online gamers ( $\mathrm{Li}$ et al. 2016), and general gamers and MOBA players (Ramos-Diaz et al. 2018). Among 26 studies, 16 studies collected data online (Király et al. 2015; Bányai et al. 2019; Šporčić and Glavak-Tkalić 2018; Loton et al. 2016; Maroney et al. 2019; von der Heiden et al. 2019; Kardefelt-Winther 2014a, b; Kaczmarek and Drążkowski 2014; Billieux 


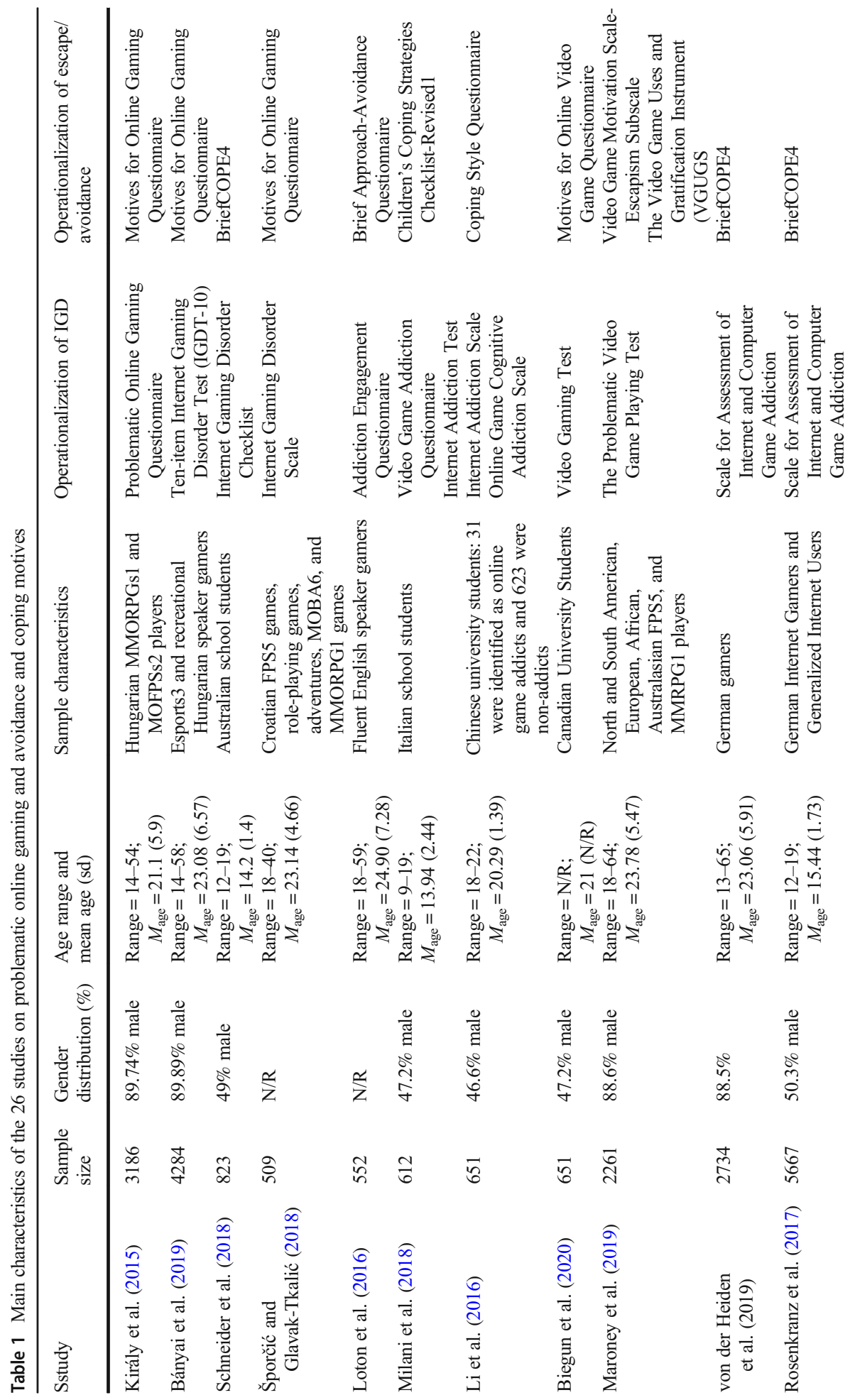




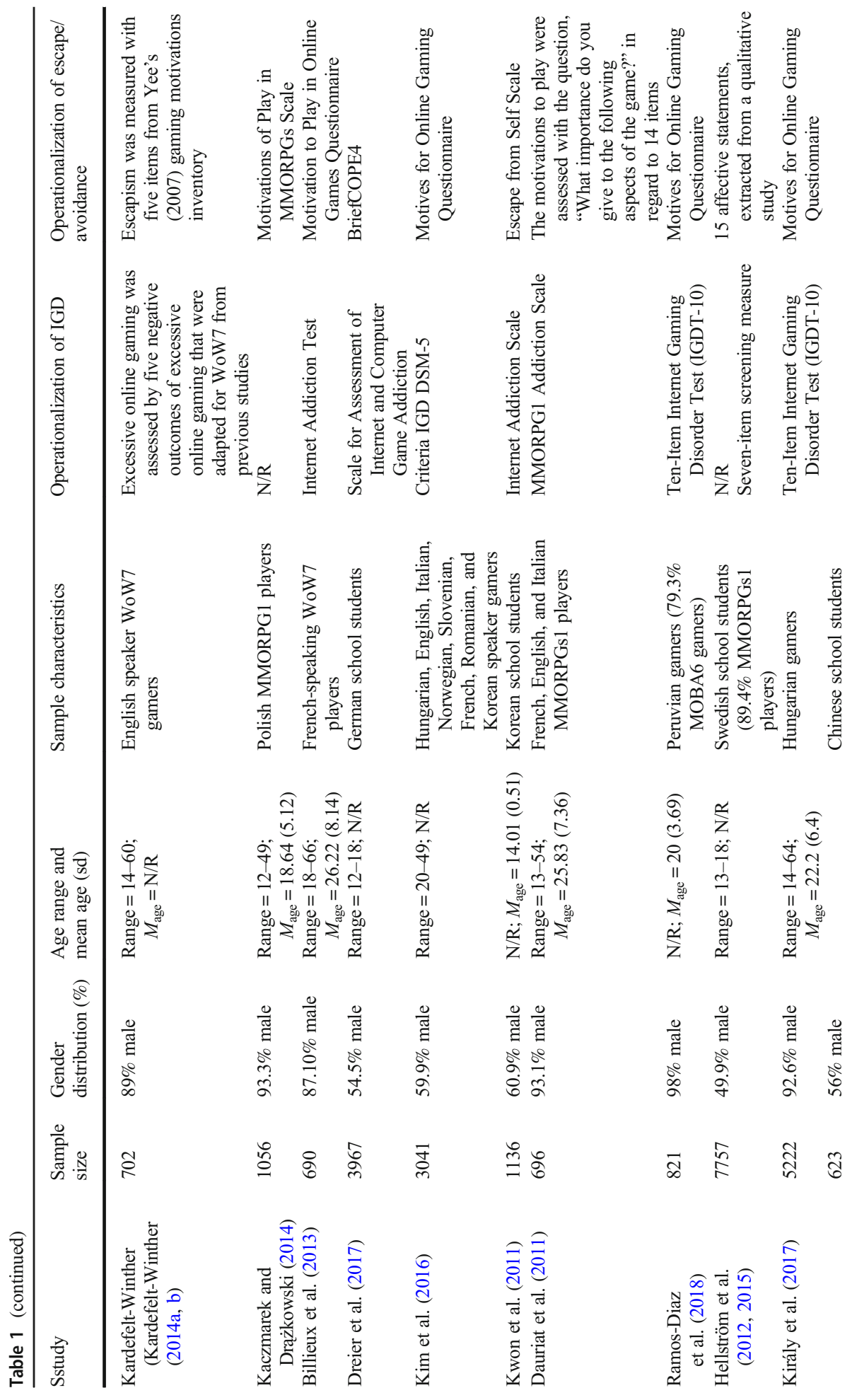




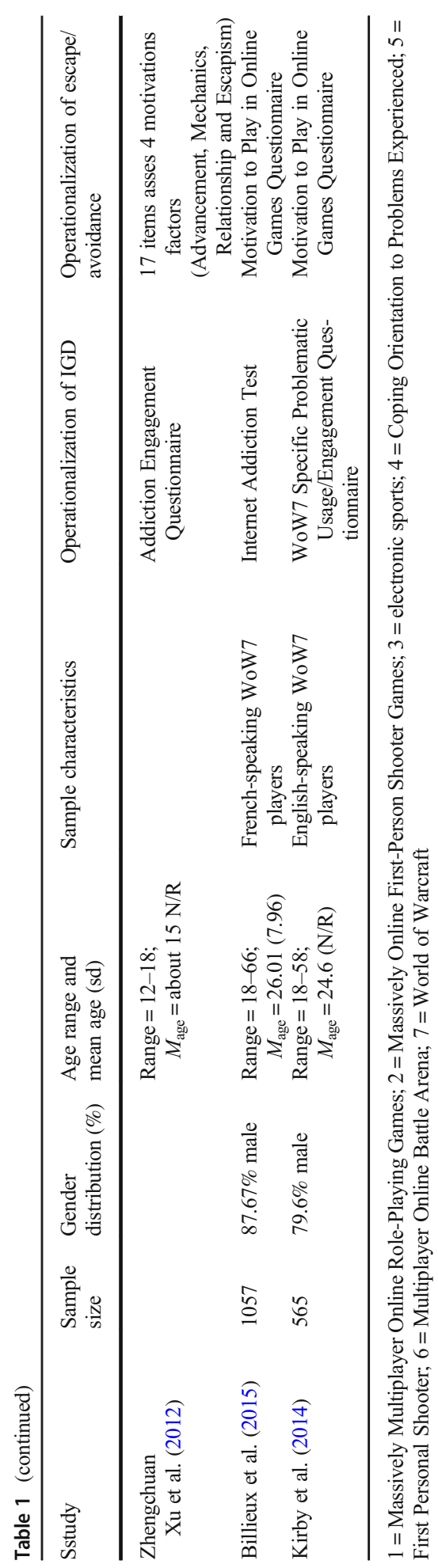


et al. 2013, 2015; Kim et al. 2016; Ramos-Diaz et al. 2018; Dauriat et al. 2011; Király et al. 2017; Kirby et al. 2014) and ten collected data offline (Schneider et al. 2018; Milani et al. 2018; Li et al. 2016; Biegun et al. 2020; Rosenkranz et al. 2017; Dreier et al. 2017; Kwon et al. 2011; Hellström et al. 2012, 2015; Xu et al. 2012).

\section{Operationalization of Problematic Gaming}

To assess problematic gaming, the measures utilized by the studies comprised the following: Ten-item Internet Gaming Disorder Test ( $n=3$; Király et al. 2017; Bányai et al. 2019; RamosDiaz et al. 2018), Scale for Assessment of Internet and Computer Game Addiction $(n=3$; Rosenkranz et al. 2017; Dreier et al. 2017; von der Heiden et al., 2019), Internet Addiction Test ( $n=3$; Billieux et al. 2013, 2015; Kwon et al. 2011), and Addiction Engagement Questionnaire ( $n=2$; Loton et al. 2016; Xu et al. 2012). Two studies did not refer to any screening measures because they did not assess problematic online gaming (Kaczmarek and Drążkowski 2014; Hellström et al. 2015). In two studies, problematic gaming was assessed using five negative gaming outcomes adapted for WoW players (Kardefelt-Winther 2014a, b). Two studies utilized a combination of two different measurements: Video Game Addiction Questionnaire and Internet Addiction Test (Milani et al. 2018) and Online Game Cognitive Addiction Scale and Internet Addiction Test ( $\mathrm{Li}$ et al. 2016). The nine remaining studies utilized the Problematic Online Gaming Addiction (Király et al. 2015), Internet Gaming Disorder Checklist (Schneider et al. 2018), Internet Gaming Disorder Scale (Šporčić and Glavak-Tkalić 2018), Video Gaming Test (Biegun et al. 2019), the DSM-5 IGD criteria (Kim et al. 2016), MMORPG Addiction Scale (Dauriat et al. 2011), Problematic Video Game Playing Test (Maroney et al. 2019), WoW Specific Problematic Usage/Engagement Questionnaire (Kirby et al. 2014), and seven-item screening measure (Hellström et al. 2012).

\section{Operationalization of Escapism/Avoidance}

Among the 26 studies, 19 assessed escapism and seven assessed avoidance coping. For those that assessed escapism, the measures utilized by the studies comprised the following: Motives for Online Gaming Questionnaire ( $n=7$; Király et al. 2015; Bányai et al. 2019; Šporčić and Glavak-Tkalić 2018; Biegun et al. 2019; Kim et al. 2016; Király et al. 2017; Ramos-Diaz et al. 2018), five items from Yee's Gaming Motivations Inventory (2007) ( $n=$ 2; Kardefelt-Winther 2014a, 2014b), Motivations to Play in Online Games Questionnaire ( $n=3$; Billieux et al. 2013, 2015; Kirby et al. 2014), Video Game Motivation ScaleEscapism subscale and Video Game Uses and Gratification Instrument $(n=1$; Maroney et al. 2019), Motivations of Play in MMORPGs Scale ( $n=1$; Kaczmarek \& Drazkowski, 2014), Escape From Self Scale ( $n=1$; Kwon et al. 2011), and a 17-item questionnaire assessing four motivation types based on the functional needs of online game playing from previous research (they mainly used Yee's 2006 motivations) ( $n=1$; Xu et al. 2012). Finally, three studies assessed escapism with specific bespoke questions rather than a psychometric measure (Dauriat et al. 2011; Hellström et al. 2012, 2015). For those that assessed avoidance coping, the measures utilized by the studies comprised the following: Brief Coping Orientation to Problems Experienced ( $n=4$; Rosenkranz et al. 2017; von der Heiden et al. 2019; Schneider et al. 2018; Dreier et al. 2017), Children's Coping Strategies Checklist-Revised-1 (Milani et al. 2018), Brief Approach-Avoidance Questionnaire (Loton et al. 2016), and Coping Style Questionnaire (Li et al. 2016). 


\section{Risk of Bias}

Table 2 summarizes the risks of bias assessed in each study. All studies (i) had cross-sectional designs that do not allow conclusions to be made about the causal relationships among variables, (ii) utilized self-report survey methodologies and therefore subject to well-known biases (e.g., social desirability, memory recall), and (iii) reported cutoff criteria based upon self-reporting that might not be reliable enough for diagnosis. Moreover, all studies, apart from two (Li et al. 2016; Dreier et al. 2017), utilized non-probability (self-selecting) sampling (e.g., no representative samples). There were also other sample biases. For instance, 13 studies had a highly imbalanced gender distribution with heavily male-dominated samples (Király et al. 2015; Bányai et al. 2019; Maroney et al. 2019; von der Heiden et al., 2019; Kardefelt-Winther 2014a, b; Billieux et al. 2013, 2015; Kaczmarek and Drążkowski 2014; Dauriat et al. 2011; Király et al. 2017; Ramos-Diaz et al. 2018; Kirby et al. 2014), and one study only collected data from urban dense areas (Milani et al. 2018). With regard to measurement bias, four studies lacked rigorous or psychometrically validated measures (Kardefelt-Winther 2014a, b; Dauriat et al. 2011; Király et al. 2017) and four have limitations due to using BriefCOPE because some of its subscales have poor internal reliability and there is a tendency to report specific strategies rather than adopting different coping styles more dynamically to deal with different problems (Schneider et al. 2018; Dreier et al. 2017; Rosenkranz et al. 2017; von der Heiden et al. 2019).

\section{Main Findings}

Table 2 also shows the main findings of each study. Among the studies reviewed, each suggested the existence of a significant relationship between escapism or avoidance coping strategies and problematic online gaming. Billieux et al. (2015) found out that the problematic online gaming is highly heterogeneous and depends on a wide range of psychological factors. One of the main factor involved factor was escapism motive. It characterized two, of the three clusters of problematic gamers that authors classified. Members of the first cluster were named "unregulated escapers" and for them, excessive use can be conceptualized as a maladaptive coping strategy serving to overcome negative effects and/or negative life events. The second cluster included individuals mainly motivated by achievement and escapism with high level of self-esteem. For them, the "virtual" self has overwhelmed the "real" self, implying a potential denial of real life and an over-involvement in virtual life. Those who played for escape motives showed high risk of depressive, musculoskeletal and psychosomatic symptoms (Hellström et al. 2015), and having several negative consequences such as troubles with parents, less sleep due to gaming, forgetting to eat, and not spending time with friends (Hellström et al. 2012). Ten studies reported that escapism was associated with (and might be a predictor of) IGD and increased time spent gaming (Király et al. 2017; Kwon et al. 2011; Xu et al. 2012; Kim et al. 2016; Kaczmarek and Drążkowski 2014; Bányai et al. 2019; Šporčić and Glavak-Tkalić 2018; Biegun et al. 2019; Ramos-Diaz et al. 2018), social anxiety, and loneliness (Kardefelt-Winther 2014b). These results were also found among MMOPRG and FPS players (Billieux et al. 2013; Dauriat et al. 2011; Maroney et al. 2019). High escapism score was associated with stronger beliefs that the virtual world is as realistic as the real world (individuals think/believe the virtual world is as real as the real world), leading to decreased offline support for real world problems and reduced levels of well-being (Kaczmarek \& Drazkowski, 2014). Moreover, escapism appears to mediate the relationships between (i) self-esteem, stress, and negative outcomes (Kardefelt-Winther 2014a, b), (ii) problematic online gaming and self-concept 


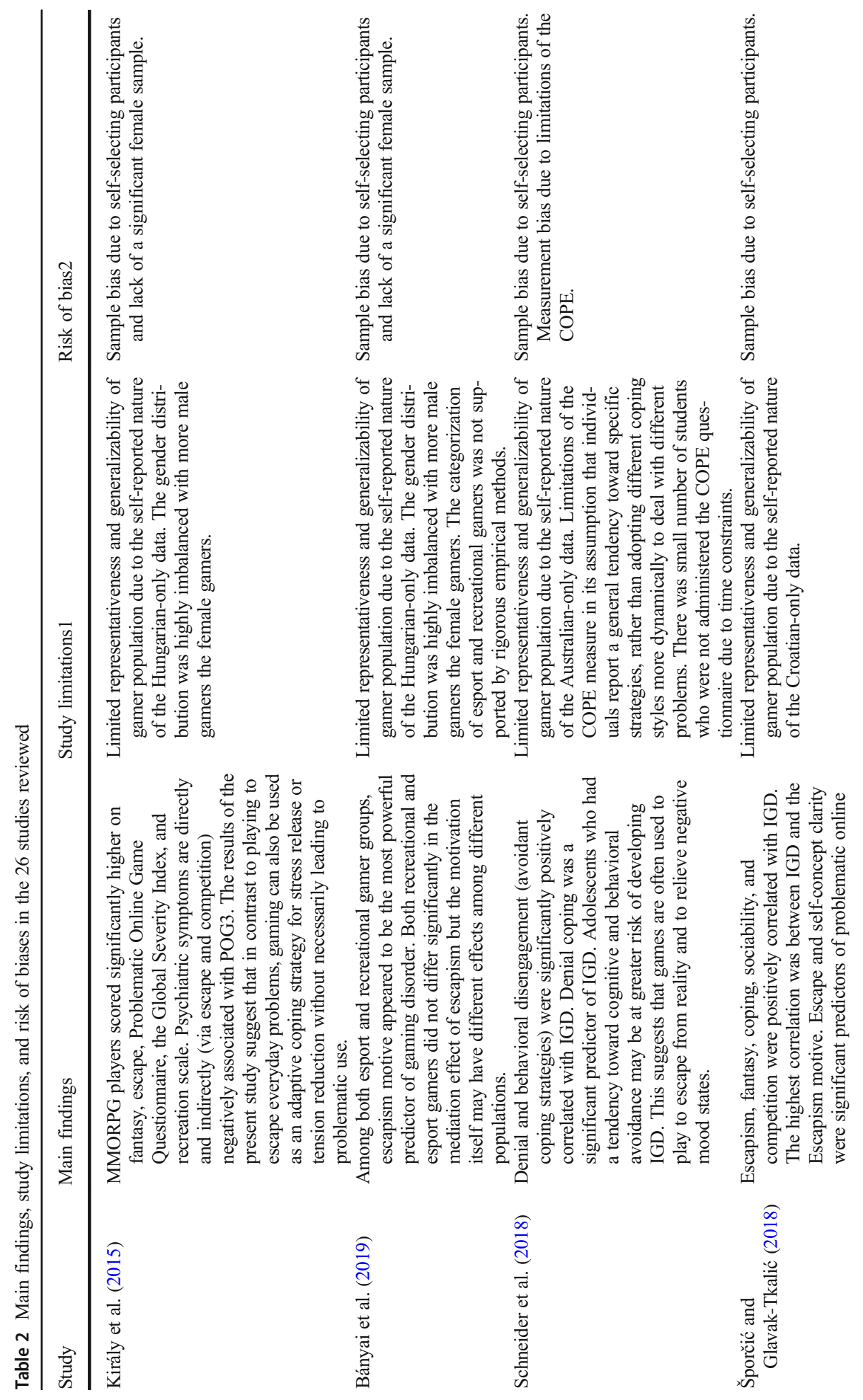




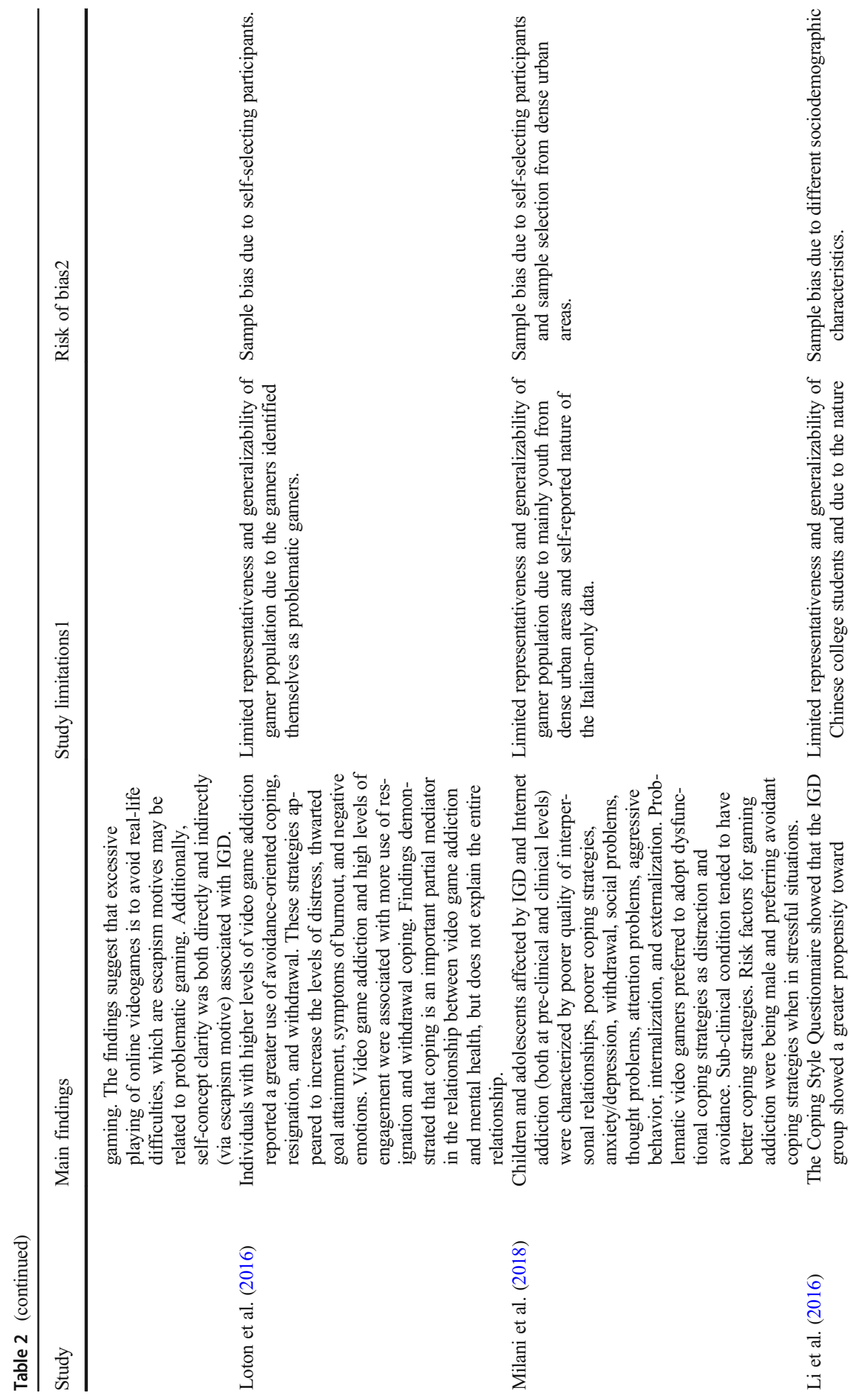




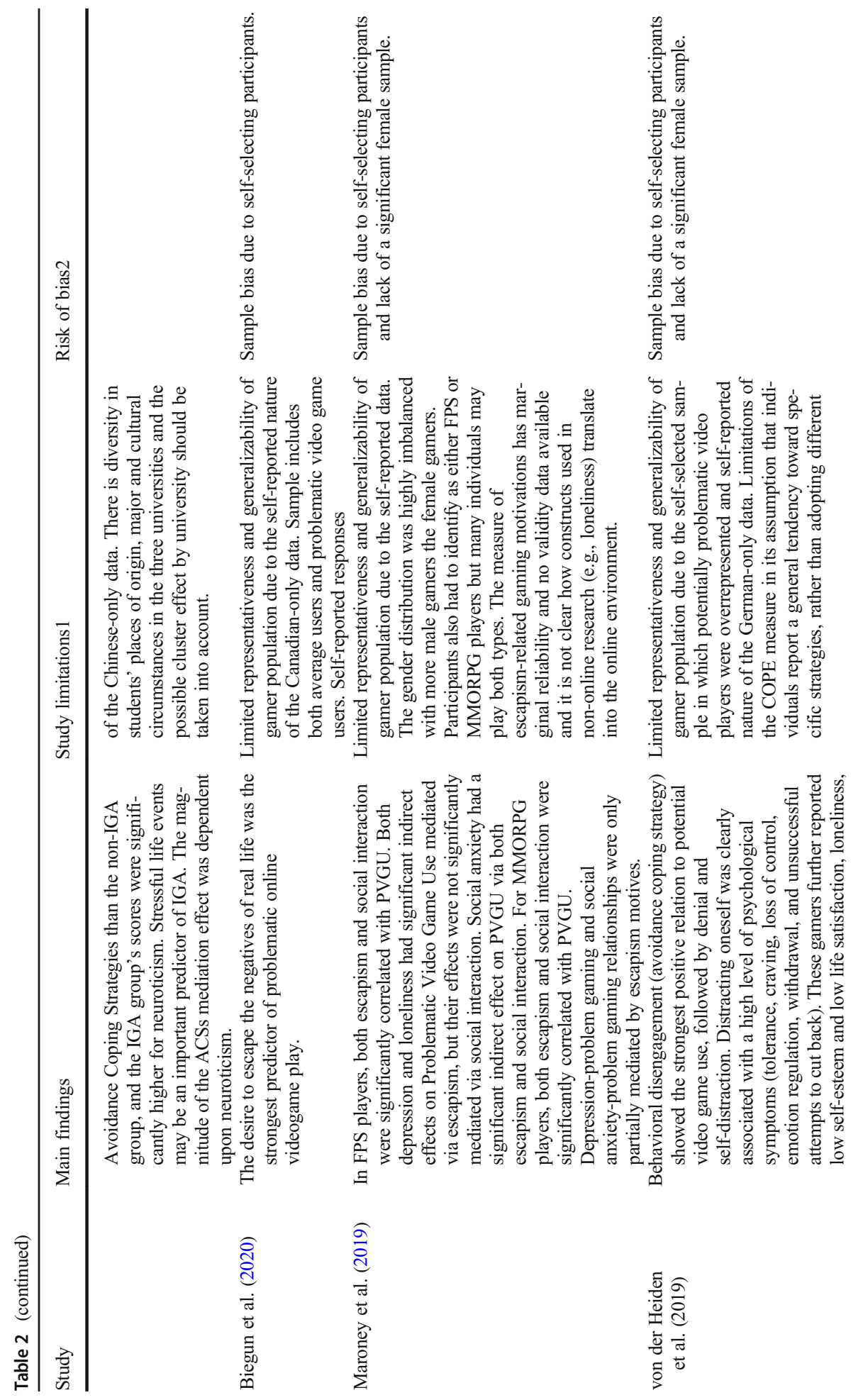




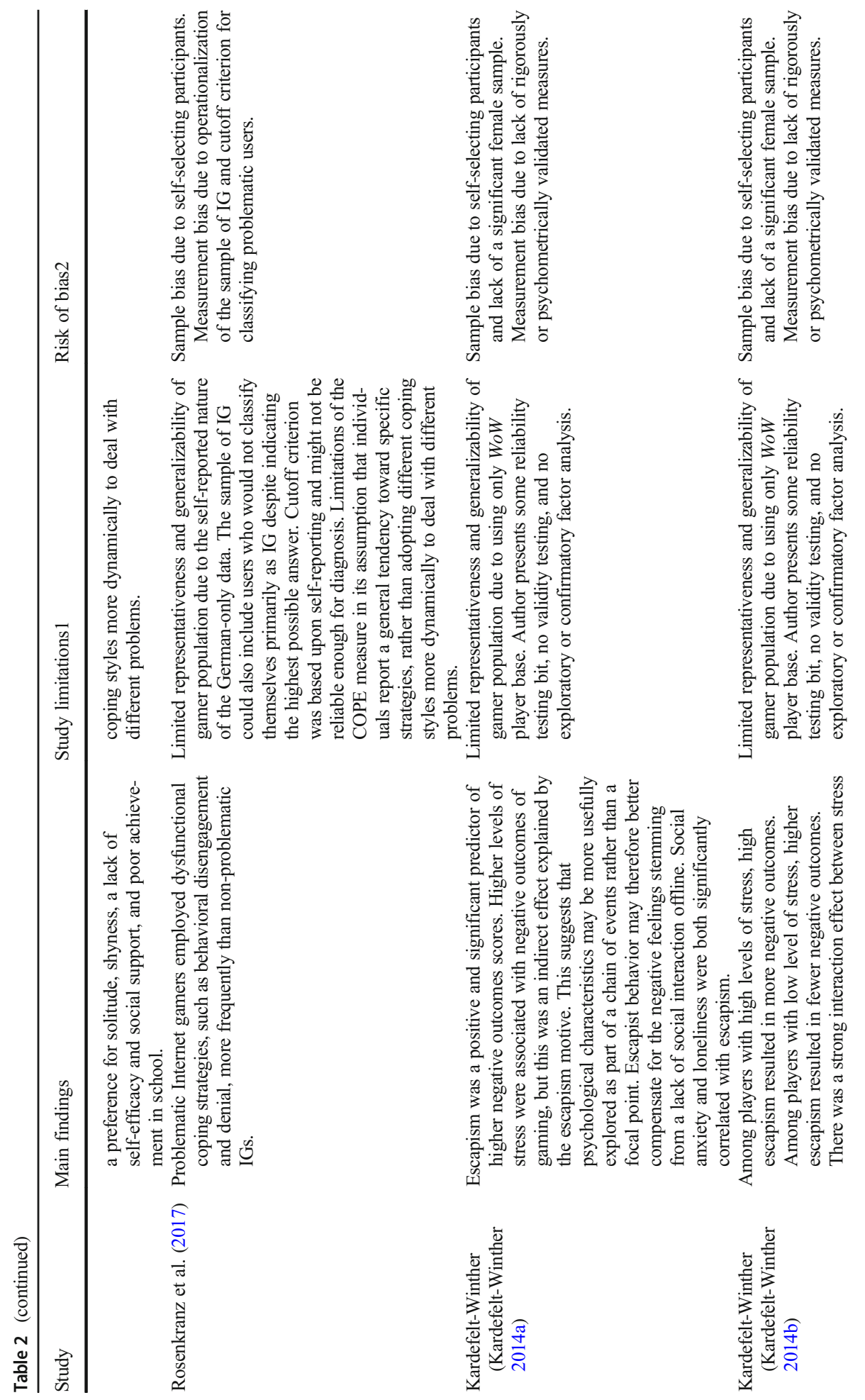




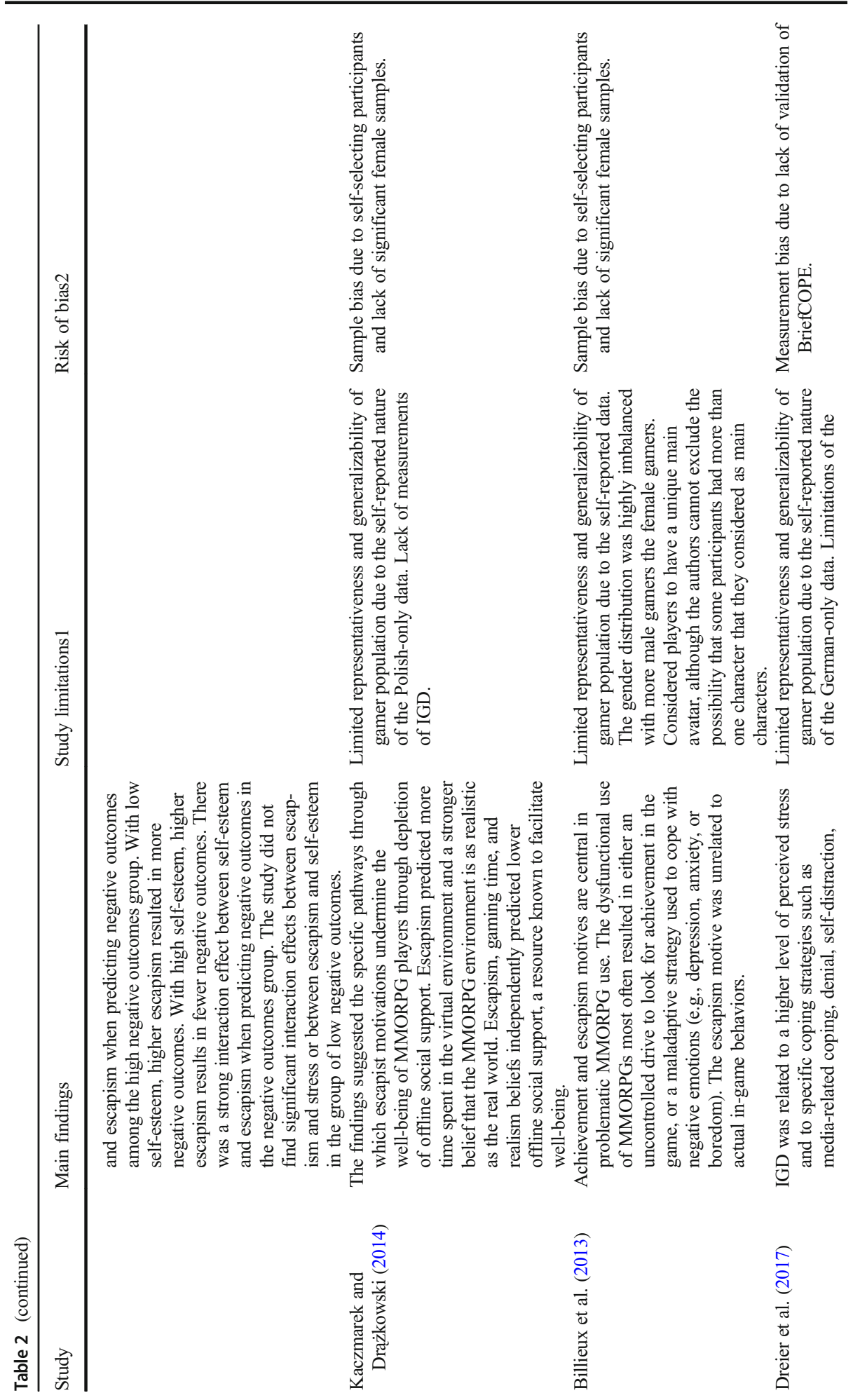




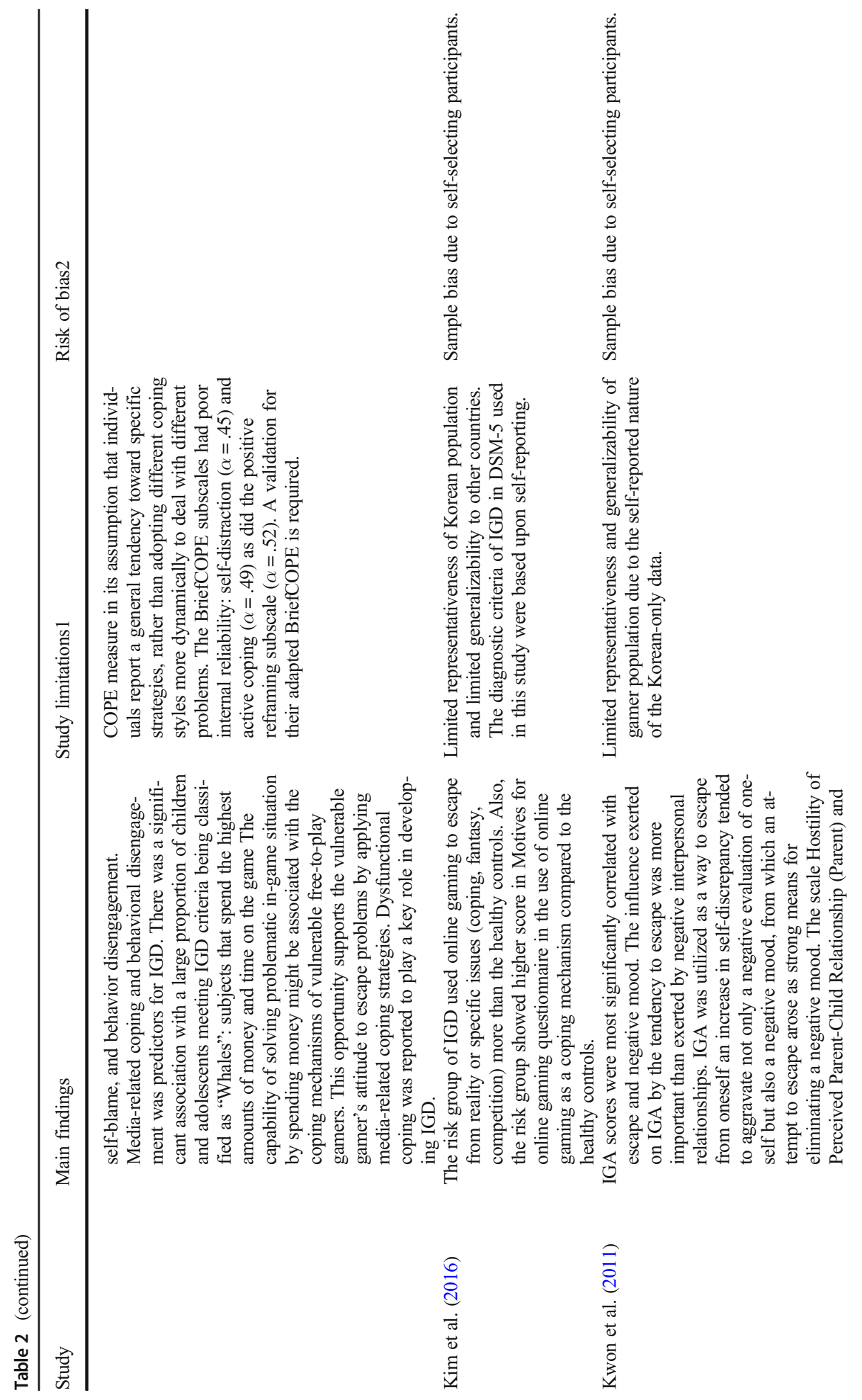




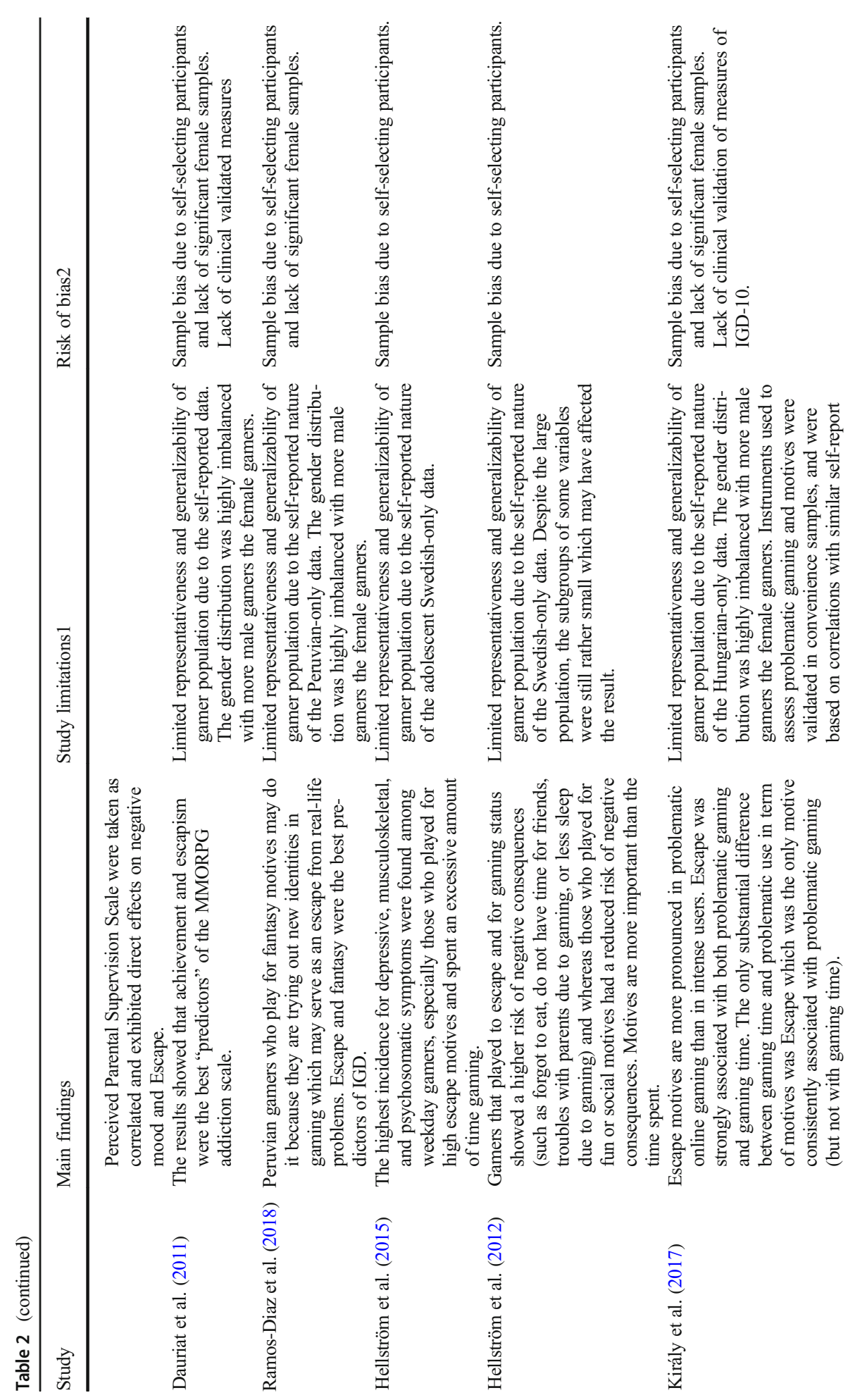




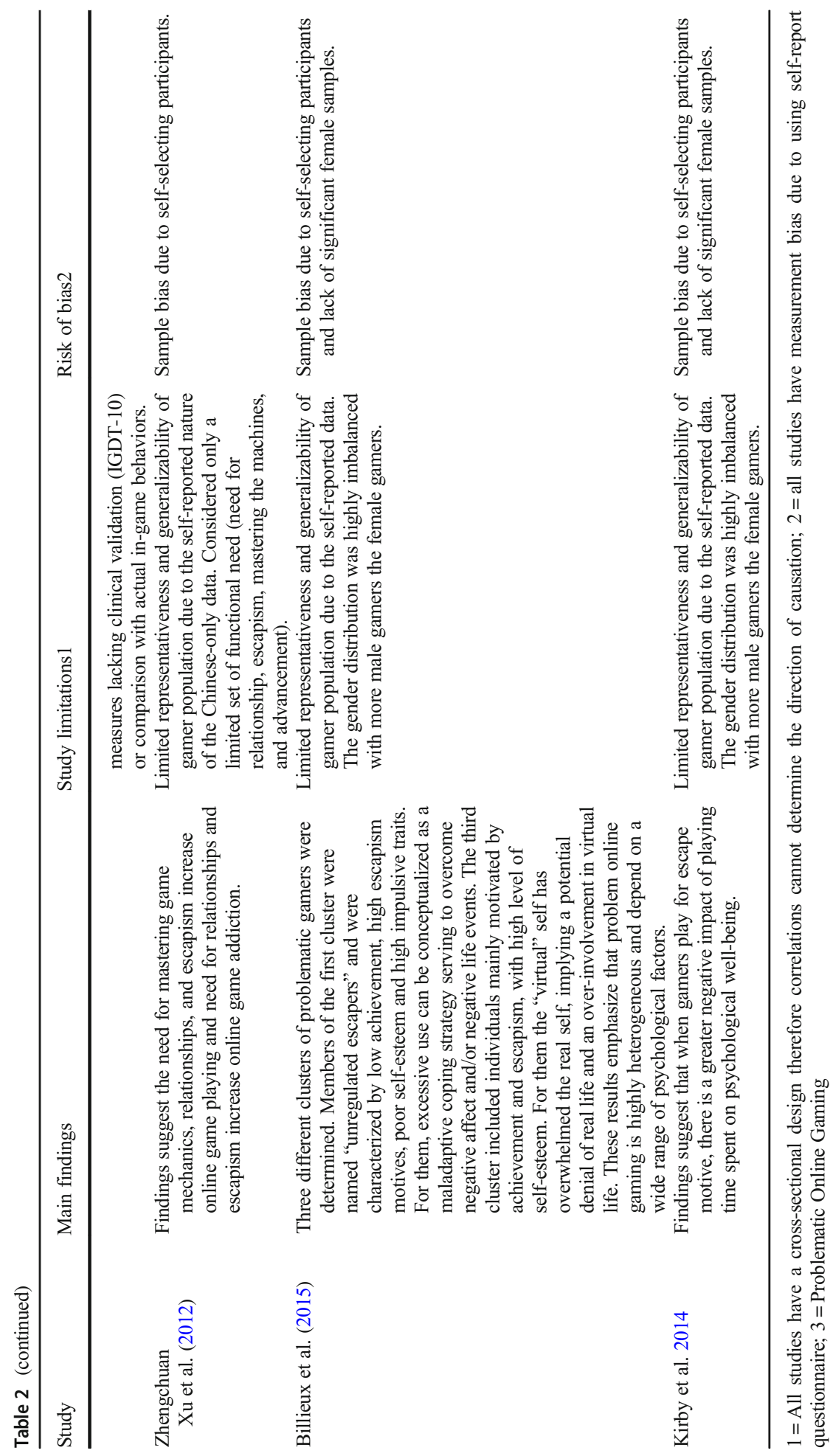


(Šporčić and Glavak-Tkalić 2018), (iii) problematic online gaming and loneliness, depression, and social anxiety (Maroney et al. 2019), and (iv) playing time spent and the its negative impact on psychological well-being (Kirby et al. 2014). Some avoidance coping strategies appear to be significant factors in problematic online gamers: self-distraction was associated with low self-esteem and life satisfaction, shyness, poor achievement at school, loneliness, and lack of self-efficacy and social support (von der Heiden et al., 2019); behavioral disengagement and denial were significant predictors of IGD (Schneider et al. 2018; Dreier et al. 2017) and were adopted by problematic gamers more frequently than non-problematic gamers (Rosenkranz et al. 2017). In addition, avoidance coping strategies mediated the relationship between IGD and negative consequences, such as level of distress, thwarted goal attainment, burnout, and negative emotion (Loton et al. 2016), and between IGD and stressful events (Li et al. 2016). Dysfunctional coping strategies, such as avoidance, might represent a risk factor for pre-clinical and clinical levels of IGD (Milani et al. 2018). Only Kiraly et al. (2015) reported that, despite MMORPG players scoring higher on escape, psychiatric symptoms (somatization, obsession compulsion, interpersonal sensitivity, depression, anxiety, hostility, phobic anxiety, paranoid ideation, and psychoticism) were both directly and indirectly, via escape, negatively associated with problematic online gaming. The authors argued gaming can also be used as an adaptive coping strategy for stress relief or tension reduction for a short time, without necessarily leading to problematic use (i.e., playing games to escape everyday difficulties appears to be a motivating behavior that can ease psychiatric distress).

\section{Discussion}

The present review identified studies that empirically investigated the role played by avoidance strategies or escape in the development of the problematic online gaming. Problematic online gaming is partly characterized by escaping from unpleasant mood states so a natural relationship was expected. The main aims of the study were to confirm the existence of this relationship and to synthesize empirical research examining the role that escapism and avoidant coping motives play in problematic online gaming. The findings suggest that escape from real-life problem or dysphoric mood is associated with several negative psychosocial and physical outcomes (Hellström et al. 2012, 2015; Kardefelt-Winther 2014b; von der Heiden et al. 2019) and might be a predictive factor of IGD (Király et al. 2017; Kwon et al. 2011, Xu et al. 2012; Kim et al. 2016; Kaczmarek and Drążkowski 2014; Bányai et al. 2019; Šporčić and Glavak-Tkalić 2018; Biegun et al. 2019; Ramos-Diaz et al. 2018; Schneider et al. 2018; Dreier et al. 2017). It is known that a wide range of psychological factors are involved in the development of problematic online gaming and the relationships between many of them are complex (Billieux et al. 2015). Many studies showed that escape and coping motives have been found to mediate the relationship between negative outcomes and several psychological factors, such as loneliness, psychiatric disorders (Maroney et al. 2019), self-concept (Šporčić and Glavak-Tkalić 2018), self-esteem, and stress (Kardefelt-Winther 2014a, b). Some of these psychological factors were more strongly associated with MMORPGs, because these games provide a virtual world where an individual can interact with players from all over the world, and completing ever higher difficulty levels motivates individuals to develop their own game skills, and the personalization of character influences the younger gamers' self-concept. This last aspect is particularly relevant for adolescents who have a self-concept that is still evolving and this might lead to a higher risk of negative outcomes. These features reinforce individuals 
with different personality characteristics. Additionally, Kaczmarek and Drążkowski (2014) pointed out that individuals who play to avoid real-life problems and experience negative mood states believe that virtual world is as real as the real world. Similarly, Warmelink et al. (2009) argued that escapism might represent complete absorption in a fantasy world, and not only a psychological distraction.

Consequently, if the motivation to go online fulfills an unsatisfied real-life need and the online applications (in this case, gaming) alleviate the offline issues, an individual may feel a strong desire to spend more time online which for a minority could lead to problematic consequences. This supports the contention that the use of internet applications may be an understandable and effective coping strategy, despite the fact that for a minority, problematic outcomes might occur. Accordingly, some researchers have argued that maladaptive coping strategies may be considered as an addiction because the coping behavior is repeatedly engaged in to avoid or manage offline problems and sometimes these are followed by negative outcomes. Such a conceptualization concerning coping and addiction suggests the formation of a vicious circle (Kardefelt-Winther 2014).

The reviewed studies have their limitations. All studies employed a cross-sectional design and it was not possible to draw causal inferences from the data about the relationship between the variables studied. Therefore, experimental methods and longitudinal designs are required for future research to provide more reliable conclusions about the causal direction of these effects. Furthermore, research in this area has tended to focus more on young male gamers (predominately due to the sampling methods used, such as online forums, websites), and this has resulted in limited generalizability of the results. A further limitation was the decision to include only studies with more than 500 participants in the review. This led to the exclusion of studies with some weaker methodologies, but possibly excluded longitudinal studies and studies using clinical samples which potentially limit the generalizability of the results. Regarding measurement biases, only self-report measures were used, which introduces wellknown biases such as social desirability and memory recall. Additionally, some studies adopted (i) the BriefCOPE (Carver 1997) in which individuals report a general tendency toward specific strategies, rather than adopting different coping styles more dynamically to deal with different problems (Rosenkranz et al. 2017; von der Heiden et al. 2019; Schneider et al. 2018; Dreier et al. 2017) or (ii) measures without rigorous or psychometric validation (Kardefelt-Winther 2014a, b). Consequently, future research should opt for different evaluation procedures such as information from parents or partners, objective measures by using new technologies, such as computer programs to monitor the individuals' game behavior, and daily diaries that would be useful to establish the extent to which everyday negative feelings, motives, and online gaming are interrelated (providing also more ecologically valid data). Finally, two further limitations should be noted. First, no specific software was used in conducting and synthesizing the papers reviewed, and second, the study was not preregistered with PROSPERO.

\section{Clinical Implications}

Overall, problematic life events or stressful situations can motivate individuals to go online and use specific applications, such as videogames, to fulfill unsatisfied needs or relieve dysphoric mood states (Kiraly et al. 2015). It is worth noting that this can lead to both positive and negative outcomes, that is, positive when the compensation is successful (feeling better and where applications have been used for short time) and negative when this mechanism 
becomes persistent and the intensity of the use compromises other areas of an individual's life. Furthermore, these are not necessarily mutually exclusive.

Therefore, the question that arises is when or for whom such motivations may be harmful. Parents, educators, and health professionals should not necessarily be worried about online gaming as a way for individuals to cope with daily stressors. However, for small minority, excessive gaming can become a problematic behavior because such motives might result in compulsive engagement in the game and result in negative real-life consequences (Young 2009). From a practical standpoint, if motivations play an important role in excessive and problematic gaming, a better understanding of how individuals attempt to cope with real-life problems and negative feelings should suggest more effective prevention and intervention measures. Studies have shown that reducing the time spent online gaming alone does not appear to be an effective intervention (Šporčić and Glavak-Tkalić 2018). In most cases, prevention programs include psycho-education interventions and tools that have the development of healthier coping strategies as the main outcome so that individuals can better manage daily life stressors (Kuss and Griffiths 2012).

The present review suggests that coping style might be a useful mechanism for the clinical formulations of problematic online gaming, leading to the development of more adaptive, problem-focused coping strategies and redirecting gaming activities toward the search for new meaningful and productive opportunities. The main goals of assisting problematic gamers should be developing awareness of the negative influences of gaming and recognizing cognitive pitfalls that lead to denial or minimizing the distress they experience in their lives (King and Delfabbro 2016). With the promulgation of prevention programs at an early age and underpinned by empirical knowledge concerning the risk factors as motivations for gaming, the greater the possibility that children and adolescents will be protected from the dangers and consequences of excessive online gaming.

\section{Compliance with Ethical Standards}

Conflict of Interest The authors declare that they have no conflict of interest. Sources of funding are acknowledged.

Ethical Approval Not applicable.

Informed Consent Not applicable.

Open Access This article is licensed under a Creative Commons Attribution 4.0 International License, which permits use, sharing, adaptation, distribution and reproduction in any medium or format, as long as you give appropriate credit to the original author(s) and the source, provide a link to the Creative Commons licence, and indicate if changes were made. The images or other third party material in this article are included in the article's Creative Commons licence, unless indicated otherwise in a credit line to the material. If material is not included in the article's Creative Commons licence and your intended use is not permitted by statutory regulation or exceeds the permitted use, you will need to obtain permission directly from the copyright holder. To view a copy of this licence, visit http://creativecommons.org/licenses/by/4.0/.

\section{References}

Alonso-Fernández, F. (1999). Le altre droghe: alimentazione sesso televisione acquisti gioco lavoro. Edizioni Universitarie Romane. 
American Psychiatric Association. (2013). Diagnostic and statistical manual of mental disorders (5th ed.). Arlington: American Psychiatric Publishing.

Armstrong, L., Phillips, J. G., \& Saling, L. L. (2000). Potential determinants of heavier Internet usage. International Journal of Human-Computer Studies, 53(4), 537-550.

Bacharach, S. B., Bamberger, P. A., \& Doveh, E. (2008). Firefighters, critical incidents, and drinking to cope: The adequacy of unit-level performance resources as a source of vulnerability and protection. Journal of Applied Psychology, 93(1), 155-169.

Bányai, F., Griffiths, M. D., Demetrovics, Z., \& Király, O. (2019). The mediating effect of motivations between psychiatric distress and gaming disorder among esport gamers and recreational gamers. Comprehensive Psychiatry, 94, 152117.

Bergevin, T., Gupta, R., Derevensky, J., \& Kaufman, F. (2006). Adolescent gambling: Understanding the role of stress and coping. Journal of Gambling Studies, 22(2), 195-208.

Biegun, J., Edgerton, J. D., \& Roberts, L. W. (2020). Measuring problem online video gaming and its association with problem gambling and suspected motivational, mental health, and behavioral risk factors in a sample of university students. Games and Culture, 20(10), 1-23 1555412019897524.

Billieux, J., Van der Linden, M., Achab, S., Khazaal, Y., Paraskevopoulos, L., Zullino, D., \& Thorens, G. (2013). Why do you play World of Warcraft? An in-depth exploration of self-ported motivations to play online and in-game behaviours in the virtual world of Azeroth. Computers in Human Behavior, 29(1), 103-109.

Billieux, J., Thorens, G., Khazaal, Y., Zullino, D., Achab, S., \& Van der Linden, M. (2015). Problematic involvement in online games: A cluster analytic approach. Computers in Human Behavior, 43, 242-250.

Blaszczynski, A., \& Nower, L. (2002). A pathways model of problem and pathological gambling. Addiction, 97(5), 487-499. https://doi.org/10.1046/j.1360-0443.2002.00015.x.

Borusiak, P., Bouikidis, A., Liersch, R., \& Russell, J. B. (2008). Cardiovascular effects in adolescents while they are playing video games: A potential health risk factor? Psychophysiology, 45(2), 327-332.

Brand, M., Laier, C., \& Young, K. S. (2014). Internet addiction: Coping styles, expectancies, and treatment implications. Frontiers in Psychology, 5, 1256.

Brand, M., Young, K. S., Laier, C., Wölfling, K., \& Potenza, M. N. (2016). Integrating psychological and neurobiological considerations regarding the development and maintenance of specific Internet-use disorders: An Interaction of Person-Affect-Cognition-Execution (I-PACE) model. Neuroscience \& Biobehavioral Reviews, 71, 252-266.

Canale, N., Marino, C., Griffiths, M. D., Scacchi, L., Monaci, M. G., \& Vieno, A. (2019). The association between problematic online gaming and perceived stress: The moderating effect of psychological resilience. Journal of Behavioral Addictions, 8(1), 174-180.

Caplan, S., Williams, D., \& Yee, N. (2009). Problematic internet use and psychosocial well-being among MMO players. Computers in Human Behavior, 25(6), 1312-1319.

Carver, C. S. (1997). You want to measure coping but your protocol's too long: Consider the brief cope. International Journal of Behavioral Medicine, 4(1), 92-100.

Compas, B. E., Connor-Smith, J. K., Saltzman, H., Thomsen, A. H., \& Wadsworth, M. E. (2001). Coping with stress during childhood and adolescence: Problems, progress, and potential in theory and research. Psychological Bulletin, 127(1), 87-127.

Cooper, M. L., Wood, P. K., Orcutt, H. K., \& Albino, A. (2003). Personality and the predisposition to engage in risky or problem behaviors during adolescence. Journal of Personality and Social Psychology, 84(2), 390410.

Dauriat, F. Z., Zermatten, A., Billieux, J., Thorens, G., Bondolfi, G., Zullino, D., \& Khazaal, Y. (2011). Motivations to play specifically predict excessive involvement in massively multiplayer online roleplaying games: Evidence from an online survey. European Addiction Research, 17(4), 185-189.

Deleuze, J., Maurage, P., Schimmenti, A., Nuyens, F., Melzer, A., \& Billieux, J. (2019). Escaping reality through videogames is linked to an implicit preference for virtual over real-life stimuli. Journal of Affective Disorders, 245, 1024-1031.

Demetrovics, Z., Urbán, R., Nagygyörgy, K., Farkas, J., Zilahy, D., Mervó, B., Harmath, E. et al. (2011). Why do you play? The development of the motives for online gaming questionnaire (MOGQ). Behavior Research Methods, 43(3), 814-825.

Donovan, C. L., \& Spence, S. H. (2000). Prevention of childhood anxiety disorders. Clinical Psychology Review, 20(4), 509-531.

Dreier, M., Wölfling, K., Duven, E., Giralt, S., Beutel, M. E., \& Müller, K. W. (2017). Free-to-play: About addicted whales, at risk dolphins and healthy minnows. Monetarization design and internet gaming disorder. Addictive Behaviors, 64, 328-333.

Ebata, A. T., \& Moos, R. H. (1991). Coping and adjustment in distressed and healthy adolescents. Journal of Applied Developmental Psychology, 12(1), 33-54. 
Entertainment Software Association (2019). Essential facts about the computer and video game industry. Retrieved from: https://www.theesa.com/esa-research/2019-essential-facts-about-the-computerand-video-game-industry/. Accessed 19 Nov 2020.

Evans, A. (2001). This virtual life: Escapism and simulation in our media world. London: Fusion Press.

Gentile, D. A., Lynch, P. J., Linder, J. R., \& Walsh, D. A. (2004). The effects of violent video game habits on adolescent hostility, aggressive behaviors, and school performance. Journal of Adolescence, 27(1), 5-22.

Griffiths, M. D. (1995). Technological addictions. Clinical Psychology Forum, 76, 14-19.

Griffiths, M. (1996). Behavioural addiction: An issue for everybody? Employee Counselling Today, 8(3), 19-25.

Griffiths, M. (1999). Violent video games and aggression: A review of the literature. Aggression and Violent Behavior, 4(2), 203-212.

Griffiths, M. D. (2005). A "components" model of addiction within a biopsychosocial framework. Journal of Substance Use, 10, 191-197.

Griffiths, M. D. (2009). The psychology of addictive behaviour. In M. Cardwell, M. L. Clark, C. Meldrum, \& A. Waddely (Eds.), Psychology for A2 level (pp. 436-471). London: Harper Collins.

Hellström, C., Nilsson, K. W., Leppert, J., \& Åslund, C. (2012). Influences of motives to play and time spent gaming on the negative consequences of adolescent online computer gaming. Computers in Human Behavior, 28(4), 1379-1387.

Hellström, C., Nilsson, K. W., Leppert, J., \& Åslund, C. (2015). Effects of adolescent online gaming time and motives on depressive, musculoskeletal, and psychosomatic symptoms. Upsala Journal of Medical Sciences, 120(4), 263-275.

Hemenover, S. H., \& Bowman, N. D. (2018). Video games, emotion, and emotion regulation: Expanding the scope. Annals of the International Communication Association, 42(2), 125-143.

Hussain, Z., \& Griffiths, M. D. (2009). The attitudes, feelings, and experiences of online gamers: A qualitative analysis. Cyberpsychology \& Behavior, 12(6), 747-753.

Kaczmarek, L. D., \& Drążkowski, D. (2014). MMORPG escapism predicts decreased well-being: Examination of gaming time, game realism beliefs, and online social support for offline problems. Cyberpsychology, Behavior and Social Networking, 17(5), 298-302.

Kardefelt-Winther, D. (2014). A conceptual and methodological critique of internet addiction research: Towards a model of compensatory internet use. Computers in Human Behavior, 31, 351-354.

Kardefelt-Winther, D. (2014a). Problematizing excessive online gaming and its psychological predictors. Computers in Human Behavior, 31, 118-122.

Kardefelt-Winther, D. (2014b). The moderating role of psychosocial well-being on the relationship between escapism and excessive online gaming. Computers in Human Behavior, 38, 68-74.

Kardefelt-Winther, D. (2017). Conceptualizing internet use disorders: Addiction or coping process? Psychiatry and Clinical Neurosciences, 71(7), 459-466.

Kardefelt-Winther, D., Heeren, A., Schimmenti, A., van Rooij, A., Maurage, P., Carras, M., Edman, J., Blaszczynski, A., Khazaal, Y., \& Billieux, J. (2017). How can we conceptualize behavioural addiction without pathologizing common behaviours? Addiction, 112(10), 1709-1715.

Katzmarzyk, P. T. (2010). Physical activity, sedentary behavior, and health: Paradigm paralysis or paradigm shift? Diabetes, 59, 2717-25.

Kim, N. R., Hwang, S. S. H., Choi, J. S., Kim, D. J., Demetrovics, Z., Király, O., Nagygyörgy, K., Griffiths, M. D., Hyun, S. Y., Youn, H. C., \& Choi, S. W. (2016). Characteristics and psychiatric symptoms of internet gaming disorder among adults using self-reported DSM-5 criteria. Psychiatry Investigation, 13(1), 58-66.

King, D. L., \& Delfabbro, P. H. (2016). The cognitive psychopathology of internet gaming disorder in adolescence. Journal of Abnormal Child Psychology, 44(8), 1635-1645.

Király, O., Urbán, R., Griffiths, M. D., Ágoston, C., Nagygyörgy, K., Kökönyei, G., \& Demetrovics, Z. (2015). The mediating effect of gaming motivation between psychiatric symptoms and problematic online gaming: An online survey. Journal of Medical Internet Research, 17(4), e88.

Király, O., Tóth, D., Urbán, R., Demetrovics, Z., \& Maraz, A. (2017). Intense video gaming is not essentially problematic. Psychology of Addictive Behaviors, 31(7), 807-817.

Kirby, A., Jones, C., \& Copello, A. (2014). The impact of massively multiplayer online role playing games (MMORPGs) on psychological wellbeing and the role of play motivations and problematic use. International Journal of Mental Health and Addiction, 12(1), 36-51.

Kuss, D. J., \& Griffiths, M. D. (2012). Online gaming addiction in children and adolescents: A review of empirical research. Journal of Behavioral Addictions, 1, 3-22.

Kuss, D. J., Louws, J., \& Wiers, R. W. (2012). Online gaming addiction? Motives predict addictive play behavior in massively multiplayer online role-playing games. Cyberpsychology, Behavior and Social Networking, $15(9), 480-485$. 
Kuss, D. J., Dunn, T. J., Wölfling, K., Müller, K. W., Hędzelek, M., \& Marcinkowski, J. (2017). Excessive Internet use and psychopathology: The role of coping. Clinical Neuropsychiatry: Journal of Treatment Evaluation, 14(1), 73-81.

Kwon, J. H., Chung, C. S., \& Lee, J. (2011). The effects of escape from self and interpersonal relationship on the pathological use of Internet games. Community Mental Health Journal, 47(1), 113-121.

Laconi, S., Pirès, S., \& Chabrol, H. (2017). Internet gaming disorder, motives, game genres and psychopathology. Computers in Human Behavior, 75, 652-659.

Lazarus, R. S., \& Folkman, S. (1984). Stress appraisal, and coping. New York: Springer Publishing.

Lemmens, J. S., Valkenburg, P. M., \& Peter, J. (2011). Psychosocial causes and consequences of pathological gaming. Computers in Human Behavior, 27(1), 144-152.

Li, H., Zou, Y., Wang, J., \& Yang, X. (2016). Role of stressful life events, avoidant coping styles, and neuroticism in online game addiction among college students: A moderated mediation model. Frontiers in Psychology, 7, 1794.

Loton, D., Borkoles, E., Lubman, D., \& Polman, R. (2016). Video game addiction, engagement and symptoms of stress, depression and anxiety: The mediating role of coping. International Journal of Mental Health and Addiction, 14(4), 565-578.

Maroney, N., Williams, B. J., Thomas, A., Skues, J., \& Moulding, R. (2019). A stress-coping model of problem online video game use. International Journal of Mental Health and Addiction, 17(4), 845-858.

Milani, L., La Torre, G., Fiore, M., Grumi, S., Gentile, D. A., Ferrante, M., et al. (2018). Internet gaming addiction in adolescence: Risk factors and maladjustment correlates. International Journal of Mental Health and Addiction, 16(4), 888-904.

Moher, D., Liberati, A., Tetzlaff, J., Altman, D. G., \& Prisma Group. (2009). Preferred reporting items for systematic reviews and meta-analyses: The PRISMA statement. PLoS Medicine, 6(7), e1000097.

Mordor Intelligence (2019). Gaming Industry - growth, trends, and forecast (2020-2025). Retrieved from: https://www.mordorintelligence.com/industry-reports/global-games-market. Accessed 19 Nov 2020.

Pontes, H. M. (2017). Investigating the differential effects of social networking site addiction and Internet gaming disorder on psychological health. Journal of Behavioral Addictions, 6(4), 601-610.

Przybylski, A. K., Rigby, C. S., \& Ryan, R. M. (2010). A motivational model of video game engagement. Review of General Psychology, 14(2), 154-166.

Ramos-Diaz, J., Ramos-Sandoval, R., Király, O., Demetrovics, Z., \& Griffiths, M. D. (2018). An exploratory study on motivational predictors in internet gaming disorder among Peruvian gamers. In 2018 IEEE Sciences and Humanities International Research Conference (SHIRCON) (pp. 1-4). Lima: IEEE.

Rohde, P., Lewinsohn, P. M., Tilson, M., \& Seeley, J. R. (1990). Dimensionality of coping and its relation to depression. Journal of Personality and Social Psychology, 58(3), 499-511.

Rosenkranz, T., Müller, K. W., Dreier, M., Beutel, M. E., \& Wölfling, K. (2017). Addictive potential of internet applications and differential correlates of problematic use in internet gamers versus generalized internet users in a representative sample of adolescents. European Addiction Research, 23(3), 148-156.

Scerri, M., Anderson, A., Stavropoulos, V., \& Hu, E. (2019). Need fulfilment and internet gaming disorder: A preliminary integrative model. Addictive Behaviors Reports, 9, 100144.

Schneider, L. A., King, D. L., \& Delfabbro, P. H. (2018). Maladaptive coping styles in adolescents with internet gaming disorder symptoms. International Journal of Mental Health and Addiction, 16(4), 905-916.

Snodgrass, J. G., Lacy, M. G., Dengah II, H. F., Eisenhauer, S., Batchelder, G., \& Cookson, R. J. (2014). A vacation from your mind: Problematic online gaming is a stress response. Computers in Human Behavior, $38,248-260$.

Šporčić, B., \& Glavak-Tkalić, R. (2018). The relationship between online gaming motivation, self-concept clarity and tendency toward problematic gaming. Cyberpsychology: Journal of Psychosocial Research on Cyberspace, $12(1), 4$.

Stein, J. A., \& Nyamathi, A. (1998). Gender differences in relationships among stress, coping, and health risk behaviors in impoverished, minority populations. Personality and Individual Differences, 26(1), 141-157.

Von Der Heiden, J. M., Braun, B., Müller, K. W., \& Egloff, B. (2019). The association between video gaming and psychological functioning. Frontiers in Psychology, 10, 1731.

Warmelink, H. J. G., Harteveld, C., \& Mayer, I. S. (2009). Press enter or escape to play. Deconstructing escapism in multiplayer gaming. In DiGRA '09 - Proceedings of the 2009 DiGRA International Conference: Breaking new ground: Innovation in games, play, practice and theory (Vol. 5). London: DiGRA.

Weinstein, A., Livny, A., \& Weizman, A. (2017). New developments in brain research of internet and gaming disorder. Neuroscience \& Biobehavioral Reviews, 75, 314-330.

$\mathrm{Xu}, \mathrm{Z}$., Turel, O., \& Yuan, Y. (2012). Online game addiction among adolescents: Motivation and prevention factors. European Journal of Information Systems, 21(3), 321-340.

Yee, N. (2006). Motivations for play in online games. CyberPsychology \& Behavior, 9(6), 772-775. 
Young, K. S. (2009). Understanding online gaming addiction and treatment issues for adolescents. American Journal of Family Therapy, 37(5), 355-372.

Zapata, A. L., Moraes, A. J. P., Leone, C., Doria-Filho, U., \& Silva, C. A. A. (2006). Pain and musculoskeletal pain syndromes related to computer and video game use in adolescents. European Journal of Pediatrics, $165(6), 408-414$.

Publisher's Note Springer Nature remains neutral with regard to jurisdictional claims in published maps and institutional affiliations. 